\title{
ADMINISTRAÇÃO, MANEJO OU GESTÃO DE UNIDADES DE CONSERVAÇÃO?
}

\author{
Helder Henrique de Faria ${ }^{1}$
}

\author{
Andréa Soares Pires ${ }^{2}$
}

Resumo: Há muitas discussões sobre o que seja 'gestão de unidades de conservação', sendo que o próprio conceito de gestão passou a ser utilizado no meio conservacionista há muito pouco tempo; o que era mais comum de se ouvir e ler eram os termos 'administração' e 'manejo'. Tendo em vista a experiência acumulada e a evolução das ciências gerenciais, os autores apresentam um apanhado teórico das áreas de administração de empresas e manejo de áreas protegidas intuindo contribuir na estruturação deste novo conceito.

\section{Introdução}

A visão e o entendimento do que venha a ser a gestão de unidades de conservação para os profissionais que levam a termo as atividades no campo e os demais profissionais que trabalham nos escritórios centrais das organizações nem sempre é a mesma, o que em alguns momentos contribui para embates e desavenças que impedem o bom desdobramento dos processos administrativos secundários, costumeiramente apoiadores do desenvolvimento dessas áreas.

\footnotetext{
${ }^{1}$ Eng. Florestal, pesquisador do Instituto Florestal/SMA. MMADRE-Unoeste. helderdefaria@gmail.com ${ }^{2}$ Bióloga, pesquisadora do Instituto Florestal/SMA.deapires@yahoo.com.br
} 
Como dantes e mais recentemente nos deparamos com situação desta natureza, quando não deveriam ocorrer, nos permitimos manifestar nossa reflexão sobre o tema visando somar para a discussão e o esclarecimento do conceito.

Os termos administração, manejo e gestão de unidades de conservação (UC) estão muito popularizados em decorrência da adoção e adaptação de palavras estrangeiras ao léxico português, da necessidade de estabelecer conceitos de domínio corrente e do simples avanço das ciências da administração. Ainda que sejam utilizados de modo semântico guardam similaridades e diferenças importantes que passamos a discorrer.

\section{Administração, manejo e gestão}

Numa concepção ampla entende-se por administração as funções de planejar, organizar, comandar, coordenar e controlar uma organização, atividades intrínsecas aos ambientes de trabalho que encerram alguma complexidade sistêmica com entrada de insumos, processamento e produção de resultados (Maximiano, 1995).

Para este autor o planejamento consiste em examinar o futuro e traçar um plano de ação de médio e longo prazo; a organização refere-se à montagem de uma estrutura humana e material para realizar as tarefas e empreendimentos inerentes aos objetivos da organização; o comando está relacionado a adoção de esquemas que mantenham o pessoal realizando as atividades inerentes para se alcançar as metas estabelecidas pelos planos; a coordenação reúne, unifica e harmoniza todas as atividades e esforços envolvidos e o controle cuida para que tudo se realize de acordo com os planos, aspectos típicos do que acontece em uma UC implantada.

Na sua visão, uma série de princípios necessitam ser preenchidos para que a administração aconteça e seja eficaz, quais sejam:

$\checkmark \quad$ Divisão de trabalho que resulte na especialização das funções e separação dos poderes;

$\checkmark \quad$ Autoridade e responsabilidade, ou seja o direito de mandar e o poder de se fazer obedecer e as sanções que acompanham o exercício do poder; 
$\checkmark \quad$ Disciplina e respeito aos acordos estabelecidos entre a organização e seus agentes;

$\checkmark \quad$ Unidade de comando, de maneira tal que cada individuo tenha apenas um superior;

$\checkmark \quad$ Unidade de direção, ou seja um só chefe e um só programa para um conjunto de operações que visam o mesmo objetivo;

$\checkmark \quad$ Subordinação do interesse individual ao interesse geral;

$\checkmark \quad$ Remuneração do pessoal de forma eqüitativa;

$\checkmark \quad$ Centralização dos poderes de decisão no chefe, que com equilíbrio será capaz de enfrentar as responsabilidades e iniciativas dos subordinados;

$\checkmark \quad$ Hierarquia e ordem;

$\checkmark \quad$ Eqüidade no tratamento dos funcionários;

$\checkmark \quad$ Estabilidade do pessoal como forma de promover seu desenvolvimento;

$\checkmark \quad$ Iniciativa e espírito de equipe.

A administração como ciência sempre se ocupou dos afazeres da organização, que inicialmente era entendida como um conjunto de cargos e tarefas, depois como conjunto de órgãos e funções para, na atualidade, se desdobrar numa complexa gama de variáveis e fatores que interagem no aprimoramento da própria ciência (Andrade, Tachizawa e Carvalho, 2000). Esses autores informam ainda que a administração evoluiu tanto que alguns autores consideram não haver área da atividade humana tão importante pelo fato de a civilização dela depender para organizar todo o esforço cooperativo do homem.

Por seu turno a palavra 'manejo' tem sido utilizada para designar uma ampla diversidade de ações e atividades desenvolvidas nas unidades de conservação, sendo um termo adotado em nosso país e restante da América Latina denotando o significado anglicano de management e manager, respectivamente administração e administrador. No dicionário português a primeira sinonímia ao termo refere-se ao ato de manipular, manusear e manear com as mãos algum objeto ou recurso, entretanto nos novos e modernos dicionários da língua é possível vislumbrar conotações empresariais e organizacionais tais como administração, gerência e direção (Ferreira, 1999), com certeza uma corroboração lingüística ao uso popular do termo.

Em termos técnicos, apresentamos a visão de alguns autores com elevada influência na América Latina. Dalfelt (1976) declarou que o manejo das áreas silvestres 
protegidas é uma ciência empenhada em buscar soluções para os diversos problemas que surgem e o desenvolvimento de metodologias para as diversas categorias de manejo existentes.

MacFarland (1980) sustenta que os componentes básicos do processo chamado manejo de áreas protegidas são: legislação, política, aquisição de terras, planejamento em vários níveis, infra-estrutura institucional, capacitação de pessoal, participação pública, pesquisa e monitoramento, implementacão de esquemas de proteção e manejo de recursos, utilização racional de recursos, operações e manutenção e finalmente, avaliação do planejado e executado. Cifuentes (1983) concorda com tal definição e acrescenta que o manejo deve levar a um aproveitamento adequado dos recursos naturais e a permanência da área a longo prazo.

Deshler (1982) definiu o manejo como o eficiente e racional uso dos recursos humanos e materiais sob a égide do planejamento, de modo que a direção alcance ou cumpra os objetivos de manejo da área. MacKinnon et al. (1990) indicam que para o manejo ser efetivo é indispensável a adoção de um plano que delimite com clareza as ações programáticas consistentes com os objetivos da área.

Milano et al. (1993) após discorrerem acerca das distinções vernaculares definiram manejo como "o conjunto de ações e atividades necessárias ao alcance dos objetivos de conservação e manejo das áreas protegidas: ou seja, em um sentido técnico, as atividades fins, aquelas que estão mais proximamente relacionadas ao termo em português, aquelas que dizem respeito ao manuseio, controle ou direção de processos nas unidades de conservação, tais como proteção, recreação, educação, pesquisa e manejo de recursos".

Exprimindo uma conceituação baseada em suas experiências e nas definições oriundas de vários outros autores, Cifuentes, Izurieta e Faria (2000) afirmam que manejo é o conjunto de ações de caráter político, legal, administrativo, de pesquisa, de planejamento, de proteção, coordenação, promoção, interpretação e educação, entre outras, que resultam no melhor aproveitamento e a permanência de uma área protegida e o cumprimento de seus objetivos.

A Lei $n^{\circ}$ 9.985, de 18 de julho de 2000, que instituiu o Sistema Nacional de Unidades de Conservação (Brasil, 2000), em seu artigo $2^{\circ}$ inciso VIII define manejo como 
"todo e qualquer procedimento que vise assegurar a conservação da diversidade biológica e dos ecossistemas", uma conceituação "guarda-chuva" suficientemente ampla para abrigar todas as tendências filosóficas.

Observa-se que se por um lado alguns autores são até certo ponto reducionistas, por restringirem o conceito às ações de proteção, recreação, educação, pesquisa e manejo de recursos; outros confundem alguns fatores envolvidos nas atividades básicas das unidades de conservação (proteção e manutenção) com serviços oferecidos pelas mesmas (interpretação, educação); entretanto todos concordam na busca de caminhos para se alcançar os objetivos que norteiam a criação e designação da área.

O conceito de manejo de áreas protegidas ganhou amplitude com o passar do tempo, provavelmente em razão do acréscimo de desafios aos gestores de UCs, mais abrangente que aquele emprestado do manejo de ecossistemas em que o objeto de análises é o ecossistema em si, com seus limites definidos e alcançáveis segundo o recorte temporo-espacial eleito pelo pesquisador.

Por outro lado, ainda que o termo manejo seja mais usual em toda a América Latina, entende-se que o mesmo condiz principalmente com a manipulação dos recursos naturais renováveis, levados a termo em determinados setores sócio-econômicos ou tipos específicos de sistemas ambientais como manejo da vegetação, manejo de fauna, manejo de solos, manejo integrado de pragas, etc. (Rodriguez, 2000).

Atualmente vimos proliferar o termo gestão de negócios, gestão empresarial, gestão ambiental, etc., e gestão de unidades de conservação, mas o que seria então a gestão? De acordo com o léxico, a palavra gestão significa o "ato de gerir ou administrar oficiosamente negócios alheios, sem mandato ou qualquer representação legal”, e a gerência cuidaria então de "supervisionar e coordenar todos os procedimentos relacionados a um produto específico" (Ferreira, 1999). Uma definição seca e destituída de profundidade, mas excetuando a inexistência de mandato legal para o sujeito das ações, esta reduzida definição se compatibiliza muito superficialmente com as funções desenvolvidas pelos diretores das UCs, já que os mesmos cuidam para que um bem público (as UCs) manifeste as atribuições inerentes a seus objetivos (produto).

Historicamente o conceito de gestão surgiu no domínio privado e diz respeito à administração dos bens possuídos por um proprietário. Significa dizer que esses bens são 
susceptíveis de apropriação por outrens, a ponto de sua administração ser confiada a terceiros; e repousando em uma relação entre um sujeito e um objeto a gestão pressupõe que o vir-a-ser do objeto submete-se aos projetos, usos e preferências do sujeito (Godard,1997).

Relativo ao território, Macedo (1994) afiança que para se garantir a sustentabilidade ambiental do espaço territorial é necessário lançar-se mão de quatro instrumentos técnicos: i) o ordenamento territorial, ii) o plano para desempenho ambiental, iii) um sistema de gestão territorial e iv) um sistema de gestão da qualidade ambiental. Os dois primeiros voltados ao planejamento ambiental, respectivamente ordenando o espaço a ser gerenciado e mantendo e garantindo os resultados da gestão. Os dois outros são referentes à gestão em si, mediante a definição da natureza da gestão, os fatores a serem controlados e os índices de desempenho esperados para o espaço gerenciado; o quarto elemento diz respeito ao estabelecimento de mecanismos de aferição e avaliação, que determinam a necessidade de reajustes no caso de tendências não desejáveis.

Este autor não define estritamente o que seja gestão, mas assegura que existem várias abordagens para se efetuar a gestão ambiental territorial, e que poucas contemplam todos os instrumentos e ferramentas necessárias à gestão total. Pois para realizar a gestão ambiental total é necessário atuar sobre todos os elementos envolvidos na transformação ambiental, realizando a gestão de cada um deles de maneira especifica, porém integrados, caso contrário seu exercício torna-se oneroso e sem resultados práticos ${ }^{3}$.

Neste contexto, a relação homem-território é um elemento que tem que ser avaliado com atenção considerando-se que a interrelação entre a sociedade e o ambiente tem gerado resultantes complexas e nem sempre de simples interpretação, o que faz com que qualquer tipo de intervenção no território ${ }^{4}$ deva ser precedida da compreensão dessas dinâmicas no sistema sob estudo (Mangano, 2002).

Para Rodriguez (2000) a gestão ambiental define-se como "a condução, direção, controle e administração do uso dos sistemas ambientais através de determinados

\footnotetext{
${ }^{3}$ Em seu livro, Macedo (1994) apresenta um fluxograma bastante completo dos diferentes componentes da gestão ambiental de territórios.

4 Território não é o espaço geográfico em sí, mas o pedaço do território utilizado, o território vivo, levando em conta a interdependência e a inseparabilidade entre a materialidade, que inclui a natureza, e o seu uso, que inclui a ação humana (Santos e Silveira, 2003).
} 
instrumentos, regulamentos, normas, financiamento e disposições institucionais e jurídicas, considerado, portanto, como um processo de articulação de ações dos diferentes agentes sociais e atores econômicos que interatuam em um espaço físico e temporal". Para o autor, a gestão de um sistema tem por objetivo assegurar seu bom funcionamento e seu melhor rendimento, mas também sua perenidade e seu desenvolvimento.

Santos (2006) apresenta uma revisão bibliográfica sobre gestão ambiental que permite reconhecer a existência de diversas interpretações e conceitos sobre o tema, dependendo das características da fonte de informação, se governo, iniciativa privada ou academia, alguns se diferenciando na própria concepção da palavra: se gestão, gerenciamento, gerência ou manejo ambiental. A seguir algumas dessas definições.

\section{Quadro 1. Algumas definições de gestão ambiental.}

\begin{tabular}{|c|c|}
\hline Definição & Autor \\
\hline $\begin{array}{l}\text { Condução, direção e controle pelo Governo do uso dos recursos naturais, através } \\
\text { de determinados instrumentos, o que inclui medidas econômicas, regulamentos e } \\
\text { normalização, investimentos públicos e financiamentos, requisitos interinstitucionais } \\
\text { e judiciais. }\end{array}$ & Selden, 1973 \\
\hline $\begin{array}{l}\text { Tarefa de administrar o uso produtivo de um recurso renovável, sem reduzir a } \\
\text { produtividade e qualidade ambiental, normalmente em conjunto com o } \\
\text { desenvolvimento de uma atividade. }\end{array}$ & Hurtubia, 1980 \\
\hline $\begin{array}{l}\text { Tentativa de avaliar valores limites das perturbações e alterações que, uma vez } \\
\text { excedidos, resultem em recuperação bastante demorada do meio ambiente, e de } \\
\text { manter os ecossistemas dentro de suas zonas de resiliência, de modo a maximizar } \\
\text { a recuperação dos recursos do ecossistema natural para o homem, assegurando } \\
\text { sua produtividade prolongada e de longo prazo. }\end{array}$ & $\begin{array}{l}\text { Interim Mekong } \\
\text { Committee, } \\
1982\end{array}$ \\
\hline $\begin{array}{l}\text { Aplicação de programas de utilização dos ecossistemas naturais ou artificiais, } \\
\text { baseada em teorias ecológicas sólidas, de modo que mantenha da melhor forma } \\
\text { possível as comunidades vegetais e/ou animais como fonte de conhecimento } \\
\text { científico e de lazer. Deve garantir que os valores intrínsecos das áreas naturais } \\
\text { não fiquem alterados para o desfrute das gerações futuras, considerando todos os } \\
\text { componentes do sistema com a mesma importância. }\end{array}$ & $\begin{array}{l}\text { Glossário de } \\
\text { Ecologia, } 1987\end{array}$ \\
\hline $\begin{array}{l}\text { Conjunto de operações técnicas e atividades gerenciais, visando assegurar que o } \\
\text { empreendimento opere dentro dos padrões legais ambientais exigidos, minimize } \\
\text { seus impactos ambientais e atenda outros objetivos empresariais, como manter um } \\
\text { bom relacionamento com a comunidade. }\end{array}$ & Sanchez, 1993 \\
\hline $\begin{array}{l}\text { Conservar os recursos naturais, evitar situações irreversíveis de degradação a meio } \\
\text { e longo prazo, evitar a contaminação e melhorar a qualidade de vida da população. }\end{array}$ & IBAMA, 1995 \\
\hline
\end{tabular}

Fonte: Santos (2004)

A autora alerta que quando a gestão ambiental está voltada para as unidades de conservação, seus objetivos estarão ligados à conservação dos recursos naturais. Ou 
seja, as palavras "recurso" e "conservação" levam ao entendimento de que os elementos naturais e ecossistemas podem e devem ser usados pelo homem para o seu bem estar. Postura diversa é a referência à "preservação dos elementos naturais", frase que pressupõe uma natureza nada ou quase nada afetada pelo homem, onde as atividades do mundo moderno não são passíveis de coexistência. O gestor ambiental e, por conseguinte, o gestor de UCs deve trabalhar na primeira perspectiva, preocupando-se em integrar a informação ecológica, social e econômica à tomada de decisões técnicas.

Enfim, para se proteger uma dada UC são necessários poucos requisitos, como as atividades de vigilância e de manutenção geral; por outro lado, para se conservar a mesma área à posteridade novos componentes são imprescindíveis ao sistema gerencial: a pesquisa científica, responsável pela possibilidade de intervenções inteligentes junto aos recursos protegidos; a educação ambiental visando o "dar a conhecer" à comunidade como um todo e angariando apoio político para as ações de conservação; forte elemento de psicologia humana para dirimir assuntos atinentes às relações interpessoais dos funcionários; relações públicas com os vizinhos e lideranças locais/regionais; interação com organizações locais e regionais, entre outras infindáveis variáveis dependentes das particularidades locais e regionais (Brito, sd; Moore, 1985; Dourojeanni, 1997; James, Green \& Paine, 1999; Milano, 1999; Jorge Pádua, 2000; Tebourgh et.all, 2002; Dourojeanni \& Jorge Pádua, 2001; Faria, 2004; Debetir, 2006 entre outros).

\section{Gestão e gestores de UCs}

Amparado nesses apontamentos técnicos e teóricos foi possível estruturar uma definição integradora para a gestão de unidades de conservação como sendo...

...o equilibrado planejamento, coordenação e controle dos componentes políticos, técnicos e operacionais e os diversos atores sociais que incidem sobre o desenvolvimento da área, de maneira a obter-se a eficácia requerida para serem atendidos os objetivos que norteiam a existência da unidade de conservação e a manutenção da produtividade dos ecossistemas por ela abrangidos (Faria, 2004).

Em outras palavras significa dizer que gestão é tudo ou quase tudo que se faz dentro e fora das unidades para se alcançar ou se aproximar dos objetivos de manejo definidos para cada uma delas. A gestão eficaz é a articulação dos elementos técnicos, 
políticos e operacionais que permite a manutenção da qualidade ambiental e o alcance dos objetivos.

A cada dia a gestão se torna mais e mais profissional, requer pessoas capacitadas em várias temáticas porque ela é generalista, eclética e desafiadora. gestor faz administração de $\mathrm{RH}$, recursos financeiros, elaboração de projetos, articulação com moradores e vizinhos, prefeitos e políticos, preside Conselhos Consultivos, faz proteção e se articula com Policia Ambiental, apaga incêndios, conduz a recepção de visitantes, faz analise de licenciamentos ambientais, elabora planos de manejo e projetos, monitora a qualidade ambiental, alguns fazem pesquisa básica e aplicada, fazem palestras, organiza eventos, etc. etc. e são os maiores responsáveis por levar e elevar a imagem institucional.

No transcorrer do tempo os gestores 'ganharam' muitas atribuições, e esse incremento, todavia, não estabilizou. Seu papel e funções estão mesclados e intrincados com os papéis de direções e gerências e, portanto, eles requerem a atenção e apoio dos escalões superiores para que possam desempenhar bem as suas funções. Para que isso aconteça a contento é necessário que o conceito de gestão seja amplamente discutido e internalizado nas organizações gestoras de UCs, com a maior pretensão de se afastar e, quiçá, imolar os sentimentos de vaidades pessoais, de competição e desconfianças geradoras de conflitos na consecução dos objetivos estabelecidos para o conjunto das unidades de conservação.

Afirmamos que as atribuições dos gestores de UCs não estão completas por acreditarmos que a natureza e a sociedade humana são dinâmicas, algumas vezes imprevisíveis e noutras pouco previsíveis, aspectos que também nos permite afirmar que todos os planos são exercícios prospectivos advindos de contemplações e analises limitadas e rasas do passado e presente que permeiam as UCs e todos os trabalhos nelas e por elas realizados. Significa dizer que, não compactuando com as crendices populares, o 'futuro a ninguém pertence', pois novos fatores e componentes podem surgir no dia-adia sem que as pessoas e o sistema estejam preparados para absorvê-los, não foram previstos nos planos ou nas competências dos gestores, aspecto que faz com que os mesmos sejam os maiores operadores do famoso conceito denominado 'gestão adaptativa'. 


\section{Periódica Eletrânica

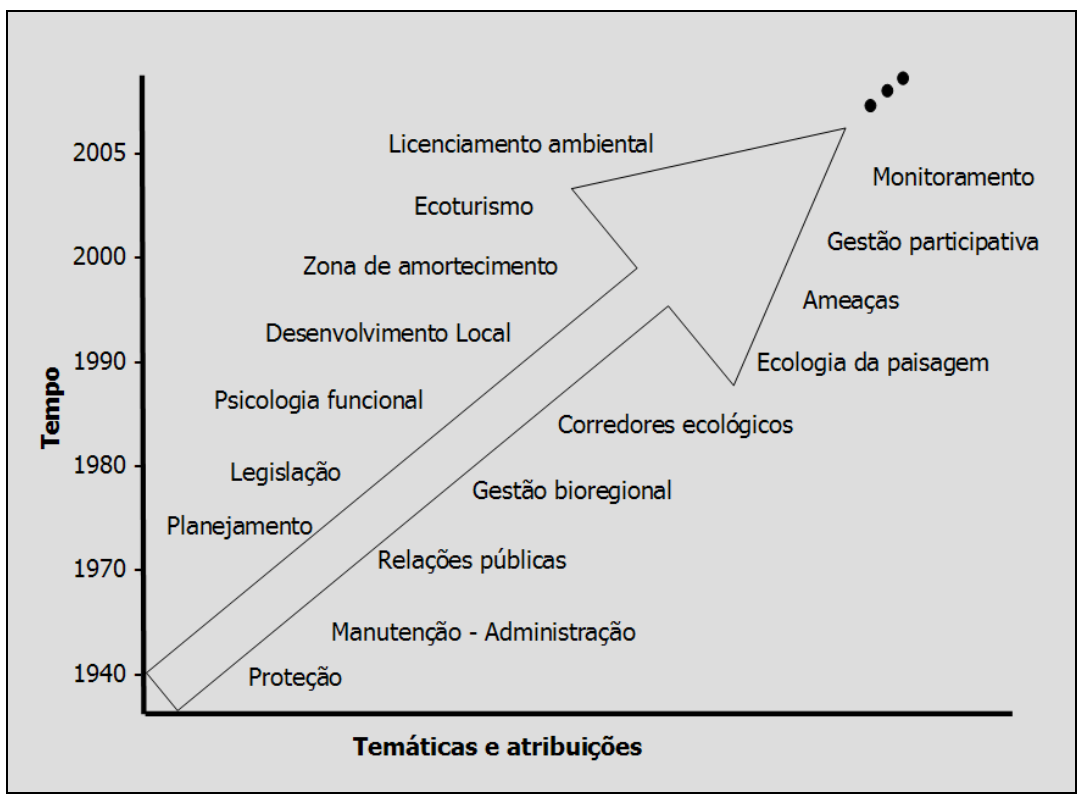

Figura 1. Elevação cumulativa das atribuições dos gestores no tempo

Observando a ilustração acima, ou revendo a história da gestão de UCs em nosso país, muito bem escrita por vários autores nacionais e estrangeiros, pode-se deduzir que no início os técnicos se preocupavam apenas com a proteção e a manutenção dessas áreas, sendo o planejamento e a administração parcialmente simples. Com o tempo a pesquisa científica descobriu os relicários guardados nessas áreas e os administradores passaram a cuidar desses interesses, nem sempre muito claros; as UCs passaram a ser mais abertas ao uso recreativo e educacional; o planejamento começou a avançar além dos limites dessas áreas; percebeu-se que o que acontecia fora dos limites influenciava a conservação do que estava dentro, avançando-se na gestão ambiental do território; as ameaças à integridade das UCs não se limitava mais à caça e a pesca, mas grandes empreendimentos e políticas de desenvolvimento governamentais desconsideravam, como até hoje acontece, a legitimidade das políticas de conservação, etc. etc.

Novos desafios sempre são interpostos à gestão de UCs e aos gestores e, portanto, suas atribuições são 'animadas' por fatores exógenos a este sistema de conservação e gerencial. Contudo há a certeza de que na atualidade os desafios estão mais fora que dentro das UCs, sendo necessário que o gestor se articule num ambiente 
multifacetado e nem sempre favorável para fazer a gestão ambiental do território em que a UC se insere.

Por estes motivos, os dirigentes de UCs de países pobres e/ou em desenvolvimento não se limitam a campos de atuação específicos; ao contrario, eles precisam ser generalistas para tratar questões muito mais amplas que as encerradas nas áreas em si mesmo, possuir visão e ação interdisciplinar, ademais de muita criatividade para 'descomplicar' a complexidade que geralmente as burocracias incutem ao ato de gerir a coisa pública.

\section{Efetivação do processo de gestão}

Para que o conceito de gestão de UCs se materialize no campo são necessários vários fatores e variáveis interdependentes, as quais didaticamente podemos agrupar em Insumos, Planejamento, Conhecimento (Pesquisa e Monitoramento), Legislação e Políticas, Uso Público e Conscientização, Governança participativa, Modernidade organizacional e Resultados (Faria, 2004; Faria e Pires 2007a, 2007b). Porém, esses e outros autores reconhecem a complexidade do tema e passam ao largo de desejar esgotar o assunto, e tampouco uma incidência generalizada desses fatores sobre todas as UCs, dado as diferentes realidades plasmadas no território brasileiro.

$\mathrm{Na}$ medida em que a gestão acontece os benefícios e serviços ambientais que as áreas naturais protegidas passam a oferecer à sociedade são muito maiores e palpáveis, uma vez que essas áreas são conduzidas a alcançar os objetivos para os quais foram criadas. Para tanto a gestão de UCs deve buscar a visão integradora, a consorciação do desenvolvimento sustentável com alternativas econômicas e sociais com fulcro na região onde se insere, dentro dos parâmetros técnicos preconizados para cada categoria de manejo legalmente reconhecida.

A vasta literatura sobre o assunto aponta que determinados insumos são imprescindíveis: funcionários e financiamento adequados; prédios onde as pessoas possam desenvolver as atividades de administração em geral; equipamentos básicos para 
transporte de pessoal e escrituração; mínima organização interna do pessoal e dos procedimentos operacionais, com uma clara estrutura de tomada de decisão; demarcação dos limites da UC de modo tal que os funcionários possuam autoridade na execução das suas lides, entre outros. A magnitude de tais componentes depende do estágio de desenvolvimento da área e da conjuntura sócio-ambiental em que está inserida, senão vejamos.

Muitas vezes ouvimos, de maneira quase generalizada, que deve existir um número ideal de funcionários por unidade de área em uma UC, porém não há um número preciso para isso, pois cada caso é um caso. O Parque Estadual da Cantareira, por exemplo, com oito mil hectares e incrustado nos limites da cidade de São Paulo, para fazer frente a toda problemática inerente a uma UC 'urbana' pode requerer tantos funcionários quanto o Parque Nacional do Jaú, na Amazônia, com dois milhões de hectares. Podemos continuar com este exercício indefinidamente, mas, na realidade, as particularidades de cada unidade influirão no desenho do que deverá ser a melhor estrutura para ela.

Além disso, para garantir uma proteção mínima, as unidades precisam possuir a situação fundiária regularizada, o que assegura o domínio institucional sobre os recursos que se deseja proteger e proporciona autoridade aos funcionários, legitimando as ações para a conservação que, somados a limites bem demarcados, melhoram o nível de proteção. Entretanto, é imprescindível a implementação de programas que considerem as comunidades do entorno ao se almejar equilibrar as implicações destes atores sobre a unidade, e vice-e-versa.

Por sua vez, para que possam ser criadas e geridas, as unidades de conservação precisam estar previstas em legislações, as quais delineiam seus horizontes vocacionais, conceituais, de manejo e desenvolvimento; principalmente quando estes diplomas são fruto de debates da sociedade, tal como foi o advento do Sistema Nacional de Unidades de Conservação, um avanço em função da instituição de boas novidades para o setor (dois distintos grupos de categorias de manejo, UCs privadas, conselhos consultivos, zonas de amortecimento, idéia de mosaico, ratificação da resolução Conama 13/1990, etc.), ainda que seja discutível a grande semelhança entre algumas das categorias de manejo. 
Muitas unidades de conservação enfrentam o problema da ausência de gestores capacitados e funcionários em quantidades suficientes para a execução das ações planejadas e requeridas à gestão e conservação da biodiversidade. É muito comum as organizações ambientais designarem apenas uma pessoa para exercer todas as atividades inerentes aos objetivos de manejo para qual a UC foi criada, acarretando um acúmulo de funções e atividades inviáveis e inexequíveis para um único profissional.

São Paulo possui belas unidades de conservação que são bem geridas graças ao empenho muitas vezes pessoal dos gestores, mas o estado possui UCs com problemas que se perpetuam há décadas (Faria, 2004; Simões e Oliveira, 2004). A instituição de uma arranjo organizacional pouco adequado ao sistema paulista, que passou todas as UCs à responsabilidade da Fundação Florestal, que até 2007 gerenciava apenas o Parque Estadual Intervales, provavelmente acirrou este problema.

Esta organização não estava preparada para o desafio que a ela sobreveio com o advento do SIEFLOR ${ }^{5}$ (São Paulo, 2006), ao contrário. Hoje apresenta lacunas em sua estrutura física e de recursos humanos, seus trâmites burocráticos não estão consolidados, o que permite variações extremas nos processos entre distintas gestões; os funcionários não contam com plano de carreira e por esta razão, por serem funcionalmente muito instáveis, se dobram a políticas às vezes equivocadas. Há indícios de que falta capacitação em seu corpo diretivo atual, com reflexos na qualidade da gestão em geral. Contudo, o sistema possui recursos financeiros razoáveis.

A propósito, uma das atuais dicotomias das organizações é a disparidade entre 0 conteúdo das mudanças que ocorrem no ambiente externo e a velocidade de respostas que surgem no seu ambiente interno. A rapidez do processo decisório e a capacidade do fazer acontecer consistem em dois dos principais atributos da rota do sucesso de qualquer empreendimento nestes próximos anos, o qual, evidentemente, se acopla à capacidade de antecipar tendências futuras da próxima mudança (Vianna e Junqueira, 1996).

\footnotetext{
${ }^{5}$ Visando dar ao sistema das UCs paulistas uma maior eficiência e eficácia, o governo do estado reformulou a estrutura gerencial das Unidades de Conservação sob responsabilidade da SMA através da edição do Decreto no 51.453, de 29 de dezembro de 2006, instituindo o Sistema Estadual de Florestas - SIEFLOR, que atribui à Fundação Florestal a gestão das UCs paulistas reconhecidas pelo SNUC.
} 


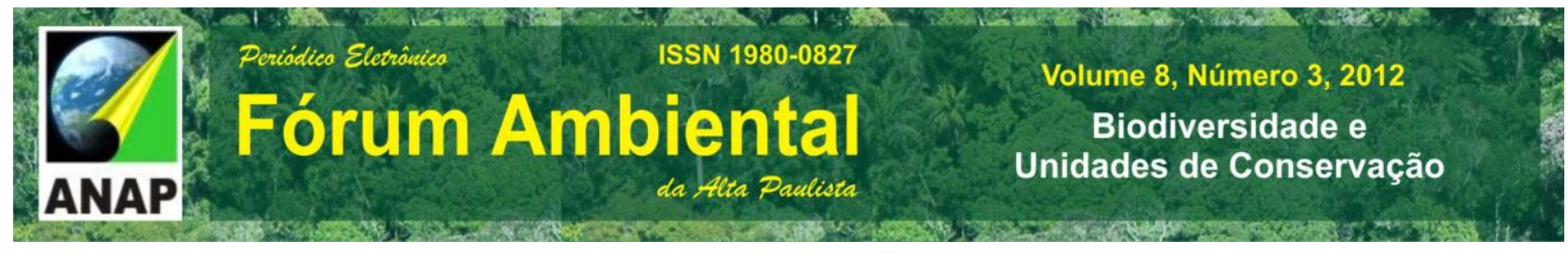

A situação na qual se encontra a Fundação Florestal neste momento, enquanto responsável pela gestão do patrimônio natural do estado, exige, como contrapartida, um novo líder, substancialmente diferente daquele dos padrões do passado, que venha para promover e fomentar as modernidades e adequações internas exigidas na atualidade.

Este novo líder precisa ter, fundamentalmente, as seguintes características e atributos: entusiasta, comprometido, humano, motivador, vontade de aprender, prazer de ensinar, visão estratégica, empreendedor, assertivo e ético (Vianna e Junqueira, 1996). Sobretudo, uma gestão moderna e eficaz das unidades de conservação requer que seus líderes e gestores possuam amplo conhecimento técnico e sistêmico, segundo a missão maior da organização.

Mas é importante ter em mente as palavras de Bergamine (1997) e considerar que mesmo com todo o conhecimento e todo o insumo necessário para se executar uma gestão de qualidade, ela pode não acontecer. E isto pode estar relacionado ao modo como a organização trata os seus funcionários; se eles, coletiva e individualmente, sentem-se parte e úteis na estrutura administrativa; se são parte do grupo social organizacional e se compõem os canais de comunicação e decisão ascendentes e descendentes; se são considerados e solicitados a emprestar suas capacidades individuais para problemas específicos da organização; se participam da formulação de políticas e diretrizes institucionais. Enfim, características comportamentais das organizações que torna o trabalho das pessoas mais agradável e são pílulas de motivação constante.

\section{Referências}

Andrade, Rui Otávio Bernardes de; Tachizawa, Takeshy; Carvalho, Ana Barreiros de. Gestão ambiental: enfoque estratégico aplicado ao desenvolvimento sustentável. São Paulo: Makron Books, 2000.

BERGAMINI, Cecília Whitaker. Motivação nas Organizações. $4^{a}$ edição. São Paulo: Ed. Atlas, 1997. 214p.

BRASIL. Lei no 9.985 de 18 de julho de 2000. Regulamenta o art. 225, § 1丷, incisos I, II, III e VII da Constituição Federal, institui o Sistema Nacional de Unidades de Conservação da Natureza e dá 


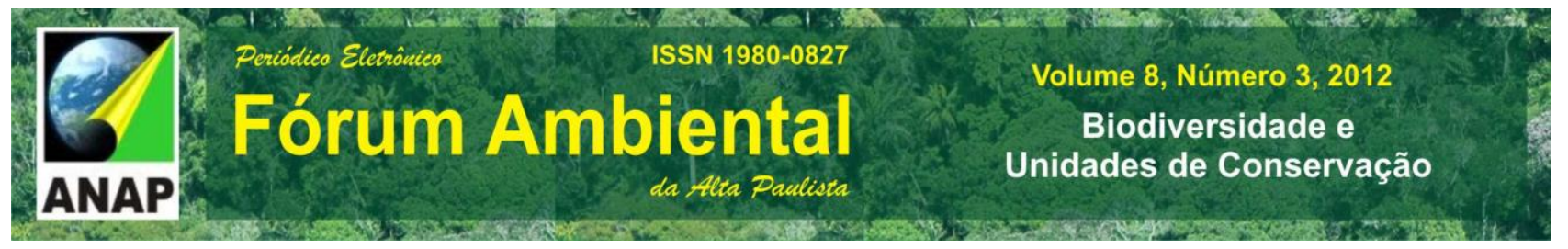

outras providências. Diário Oficial da República Federativa do Brasil. Brasília, 19 de jul. 2000. Seção I. p. 12026-12027.

BRASIL. Leis, decretos, etc. Resolução CONAMA no 013, de 06 de dezembro de 1990. Regulamenta a questão de atividades em áreas circundantes às unidades de conservação IN: CONSELHO NACIONAL DO MEIO AMBIENTE. Resoluções do CONAMA: 1984 a 1991. $4^{\text {a }}$ ed. rev. Brasília: IBAMA, 1992. p.226-227.

Brito, Maria Cecília Wey. et al. Diagnóstico - Unidades de Conservação. Série Biodiversidade do Estado de São Paulo. São Paulo, SP: Secretaria do Estado do Meio Ambiente. Programa Estadual para a Conservação da Biodiversidade. PROBIO/SP, sd.

Cifuentes, Miguel. Determinación de capacidad de carga turística en áreas protegidas. Série Técnica. Informe Técnico nํ194. Turrialba, Costa Rica: CATIE., 1992. 22p.

Cifuentes, Miguel; IZURIETA, Arturo y De FARIA, Helder Henrique. Medición de la efectividad del manejo de áreas protegidas. Serie Tecnica $\mathrm{n}^{\circ}$ 2. Turrialba, Costa Rica: WWF, GTZ, UICN. Forest Innovations Project, 2000.100p.

Dalfelt, Arne. Principios del manejo y planificación de áreas protegidas. Turrialba, C.R: CATIE, 1976. 12 p.

Debetir, Emiliana. Gestão de unidades de conservação sob influência de áreas urbanas: diagnóstico e estratégias de gestão na llha de Santa Catarina - Brasil. Tese de doutoramento. Programa de Pós-Graduação em Engenharia Civil. Universidade Federal de Santa Catarina. Florianópolis, SC. 2006. 247 p.

Deshler, Willian $O$. A systematic approach to effective management of protected areas. IN: $3^{\text {rd }}$ WORLD NATIONAL PARKS CONGRESS: MANAGING PROTECTED AREAS WORKSHOP. Actas. Bali, Indonésia: PNUD/WWF/UNESCO/FAO,1982. 20 p.

Dourojeanni, Marc J. Areas Protegidas: Problemas Antiguos y Nuevos, Nuevos Rumbos. IN: CONGRESSO BRASILEIRO DE UNIDADES DE CONSERVAÇÃO. 15 a 23 de novembro de 1997, Curitiba , PR. Anais...Curitiba , PR: Instituto Ambiental do Paraná. Universidade Livre de Meio Ambiente, 1997. Volume 1. 1997. p. 69-109.

Dourojeanni, Marc J. e JORGE PADUA, Maria Tereza. Biodiversidade: a hora decisiva. Curitiba, PR: Editora UFPR. 2001. Serie Pesquisa nํ⒌ 308p.

Faria, H. H. de \& PIRES, A. S. Atualidades em Gestão de Unidades de Conservação. In Unidades de Conservação: Gestão e Conflitos. Org. Dora Orth e Emiliana Debetir. Editora Insular. Florianópolis, SC. 2007a. pg. 11-41.

Faria, H. H. de. Eficácia de gestão de Unidades de Conservação gerenciadas pelo Instituto Florestal de São Paulo, Brasil. Tese de doutoramento. Depto. Geografia. Faculdade de Ciências e Tecnologia. UNESP. Presidente Prudente, SP. 2004. 401p.

Faria, H. H. de. Monitoramento em unidades de conservação: imperativos para a excelência da gestão. In Unidades de conservação: Ações para valorização da biodiversidade. Instituto Ambiental do Paraná. 2006. 348 p. 326-342p.

Faria, H. H. de; PIRES, A. S. Gestão de unidades de conservação: Conceituação e componentes básicos para a excelência do processo. Anais do $\mathrm{V}$ Congresso Brasileiro de Unidades de Conservação. Fundação O Boticário de Proteção à Natureza. 17 a 21 de junho de 2007b. Foz do Iguaçu, Brasil. Pg. 54 c/ CD Roon. ISSS 1677-1486.

Ferreira, Aurélio Buarque de Holanda. Novo Aurélio Século XXI: 0 dicionário da língua portuguesa. 3ª edição. Rio de Janeiro, RJ: Ed. Nova Fronteira, 1999. 2128p. 
Godard, Oliver. A gestão integrada dos recursos naturais e do meio ambiente: conceitos, instituições e desafios de legitimação. IN: VIEIRA, Paulo Freire e WEBER, Jacques (Org.). Trad. por Anne Sophie de Pontbriand-Vieira e Christilla de Lassus. Gestão de recursos naturais renováveis e desenvolvimento: Novos desafios para a pesquisa ambiental. São Paulo, SP: Cortez Editora. 1997. p. 201-267.

James, Alexander N.; Green, Michael J.B. e Paine, James. A global review of protected area budgets and staff. World Conservation Monitoring Centre. WCMC Biodiversity series $n^{\circ} 10$. Cambridge, UK: World Conservation Press. 1999.46p.

Jorge Padua, Maria Tereza. Na surdina estão nos tirando o Parque Nacional do Araguaia. Informativo da Rede Nacional Pró-Unidades de Conservação. Curitiba: 2001. 1(1): 7.

Macedo, Ricardo Kohn de. Gestão ambiental: os instrumentos básicos para a gestão ambiental de territórios e de unidades produtivas. Rio de Janeiro, RJ. Ed. ABES, 1994. 284p.

MacFarland, Craig. Componentes básicos del proceso Ilamado "Manejo". IN: SEMINARIO Forestal CATIE/DDA. Actas. Compilado por J. Combe y H. Jimenez Saa. Serie Técnica. Turrialba, C.R.: CATIE, 1980. 6: 79-82.

MacKinnon, John et al. Manejo de áreas protegidas en los trópicos. México, DF: Trad. y ed. por Biocenosis., 1990. 314 p.

Mangano, Stefania. Evolución del concepto de planificación territorial en Italia. Terra Livre. São Paulo, SP. 2002. 18(1):85-94.

Maximiano, Antônio Carlos A. Introdução à administração. $4^{a}$ edição. São Paulo, SP: Ed. Atlas, 1995. 476p.

Milano, Miguel Sereudik. Unidades de Conservação no Brasil: Mitos e Realidade. IN: $3^{O}$ CONGRESSO INTERNACIONAL DE DIREITO AMBIENTAL: A PROTEÇÃO JURÍDICA DAS FLORESTAS TROPICAIS. Anais... 30 de maio a 02 de junho de 1999. São Paulo, SP: Ed. Antonio Hermann de Vasconcelios e Benjamin, 1999. Vol. I. p. 307-316.

Milano, Miguel Sereudik; BERNARDES, Ângela Tressinari e FERREIRA, Luis M. Possibilidades alternativas para o manejo e o gerenciamento das unidades de conservação. Brasília,BR: IBAMA/ PNMA, 1993. $123 \mathrm{p}$.

Miller, Kenton R. Balancing the Scales. Guidelines for Increasing Biodiversity's Chances Througt Bioregional Management. Washington DC: World Resources Institute, 1996. 73p.

Moore, Alan W. Manual de Operaciones para Sistemas de Áreas Protegidas. Directrizes para los Países en desarrollo. Organización de las Naciones Unidas para la Agricultura y la Alimentación. Guia FAO Conservación no 9. Roma, Itália, 1985. 109p.

Rodriguez, Jose M. M. Planificación y gestión ambiental. Ministério de Educación Superior. Universidad de La Habana. Facultad de Geografia. Apostila de Curso. 2000. 53p.

Santos, Milton e SILVEIRA, Maria Lúcia. O Brasil: Território e sociedade no início do século XXI. Editora Record. 5a edição. Rio de Janeiro: 2003. 473p.

Santos, Rosely F. dos. Planejamento Ambiental. Teoria e prática. Ed. Oficina de Textos. 1a edição, $2^{\mathrm{a}}$ reimpressão. São Paulo, Br. 2004. 184p.

São Paulo. Decreto $n^{\circ} .51 .453$ de 29 de dezembro de 2006. Cria o Sistema Estadual de Florestas - SIEFLOR e dá outras providências. Diário Oficial do Estado, Poder executivo, Seção I. 2006. 116(247):37-38. 
Simões, Luciana Lopes; Oliveira, Luis Roberto Numa de. RAPPAM - Implementação da avaliação rápida e priorização do manejo de unidades de conservação do Instituto Florestal e da Fundação Florestal de São Paulo. WWF, PPMA, Fundação Florestal, Instituto Florestal. São Paulo, 2004. 42 p.

Vianna, Marco Aurelio F. e Junquiera, L.A. Costacurta. Gerente Total. Como administrar com eficácia no século XXI. Editora Gente. São Paulo, Brasil. 1996 